University of Wollongong

Research Online

Faculty of Engineering - Papers (Archive)

Faculty of Engineering and Information

Sciences

$1-1-2012$

\title{
Inelastic stability analysis of high strength rectangular concrete-filled steel tubular slender beam-columns
}

Vipulkumar Ishvarbhai Patel

Victoria University

Qing Quan Liang

Victoria University

Muhammad N. S Hadi

University of Wollongong, mhadi@uow.edu.au

Follow this and additional works at: https://ro.uow.edu.au/engpapers

Part of the Engineering Commons

https://ro.uow.edu.au/engpapers/4422

\section{Recommended Citation}

Patel, Vipulkumar Ishvarbhai; Liang, Qing Quan; and Hadi, Muhammad N. S: Inelastic stability analysis of high strength rectangular concrete-filled steel tubular slender beam-columns 2012, 91-104.

https://ro.uow.edu.au/engpapers/4422

Research Online is the open access institutional repository for the University of Wollongong. For further information contact the UOW Library: research-pubs@uow.edu.au 


\title{
Inelastic stability analysis of high strength rectangular concrete-filled steel tubular slender beam-columns
}

\author{
Vipulkumar Ishavarbhai Patel ${ }^{1}$, Qing Quan Liang*1 and Muhammad N.S. Hadi ${ }^{2}$ \\ ${ }^{1}$ School of Engineering and Science, Victoria University, PO Box 14428, Melbourne, VIC 8001, Australia \\ ${ }^{2}$ School of Civil, Mining and Environmental Engineering, University of Wollongong, Wollongong, \\ NSW 2522, Australia
}

(Received July 15, 2011, Revised November 8, 2011, Accepted April 4, 2012)

\begin{abstract}
There is relatively little numerical study on the behavior of eccentrically loaded high strength rectangular concrete-filled steel tubular (CFST) slender beam-columns with large depth-to-thickness ratios, which may undergo local and global buckling. This paper presents a multiscale numerical model for simulating the interaction local and global buckling behavior of high strength thin-walled rectangular CFST slender beam-columns under eccentric loading. The effects of progressive local buckling are taken into account in the mesoscale model based on fiber element formulations. Computational algorithms based on the Müller's method are developed to obtain complete load-deflection responses of CFST slender beam-columns at the macroscale level. Performance indices are proposed to quantify the performance of CFST slender beam-columns. The accuracy of the multiscale numerical model is examined by comparisons of computer solutions with existing experimental results. The numerical model is utilized to investigate the effects of concrete compressive strength, depth-to-thickness ratio, loading eccentricity ratio and column slenderness ratio on the performance indices. The multiscale numerical model is shown to be accurate and efficient for predicting the interaction buckling behavior of high strength thin-walled CFST slender beam-columns.
\end{abstract}

Keywords: concrete-filled steel tubes; high strength materials; inelastic analysis; local buckling.

\section{Introduction}

Although high strength thin-walled rectangular concrete-filled steel tubular (CFST) slender beamcolumns are frequently used in high rise composite buildings, the understanding of their fundamental behavior is still not sufficient and efficient analysis and design methods have not been developed owing to the lack of experimental and numerical research on this type of composite columns. The use of the high strength thin-walled steel tubes leads to economical designs but causes local buckling, which reduces the ultimate loads of CFST columns. The effects of progressive local bucking have not been considered in existing nonlinear inelastic methods of analysis for CFST slender beam-columns. These methods may overestimate the ultimate loads of CFST beam-columns. This paper aims to develop a multiscale numerical model for simulating the interaction behavior of

\footnotetext{
* Corresponding author, Ph.D., E-mail: Qing.Liang@vu.edu.au
} 
local and global buckling of high strength thin-walled CFST slender beam-columns under combined axial load and bending.

Experimental studies on the behavior of CFST short columns have been conducted by many researchers (Schneider 1998, Han 2002, Hu et al. 2003, Sakino et al. 2004, Ellobody et al. 2006). However, experimental studies on high strength thin-walled CFST slender beam-columns under axial load and bending have been very limited. Bridge (1976) undertook tests to examine the effects of eccentricity, column slenderness ratio and biaxial bending on the behavior of normal strength square CFST slender beam-columns. Shakir-Khalil and Zeghiche (1989) presented experimental results of normal strength CFST slender beam-columns under axial load and bending. Zhang et al. (2003) and Liu $(2004,2006)$ performed tests on the behavior of high strength rectangular CFST beam-columns under eccentric loading.

Compared to experimental methods, numerical analysis techniques are cost-effective tools that can be used to predict the behavior of high strength CFST slender beam-columns. Lakshmi and Shanmugam (2002) proposed a semi-analytical model for the inelastic analysis of CFST slender beam-columns under biaxial bending. However, their model did not consider the effects of local buckling, concrete confinement and concrete tensile strength. Liang $(2009 \mathrm{a}, \mathrm{b})$ developed a performance-based analysis (PBA) technique for simulating the behavior of thin-walled CFST short beam-columns under axial load and biaxial bending. The PBA technique accounts for the effects of progressive local buckling. Moreover, Liang (2011a,b) developed numerical models for the nonlinear analysis of high-strength circular CFST slender beam-columns under eccentric loading.

Multiscale models have been developed for predicting the behavior of reinforced and prestressed concrete walls (Laskar et al. 2009) and of reinforced concrete beams (Nagarajan et al. 2010). In this paper, a multiscale numerical model is presented for simulating the interaction buckling behavior of high strength thin-walled rectangular CFST slender beam-columns under eccentric loading. The mesoscale model is described, which is based on the accurate fiber element method and incorporates the material models and the effects of local and post-local buckling of steel tube walls under stress gradients. Computational procedure is presented that implements the macroscale model for predicting the load-deflection responses of CFST slender beam-columns. Performance indices are used to quantify the performance of high strength concrete and steel tube and strength reduction due to column slenderness ratio. The verification and applications of the multiscale model are provided.

\section{Mesoscale simulation}

\subsection{Fiber element model}

The mesoscale model is developed to simulate the inelastic behavior of composite cross-sections and is based on the accurate fiber element method (Liang 2009a). The rectangular CFST beamcolumn section is discretized into fiber elements as depicted in Fig. 1. Each fiber element can be assigned either steel or concrete material properties. The model assumes that plane section remains plane after deformation, which leads to a linear strain distribution through the depth of the section. The fiber strains can be calculated from the curvature $(\phi)$ and the neutral axis depth $\left(d_{n}\right)$. Fiber stresses are calculated from fiber strains using the material uniaxial stress-strain relationships. 
Inelastic stability analysis of high strength rectangular concrete-filled steel tubular slender beam-columns 93

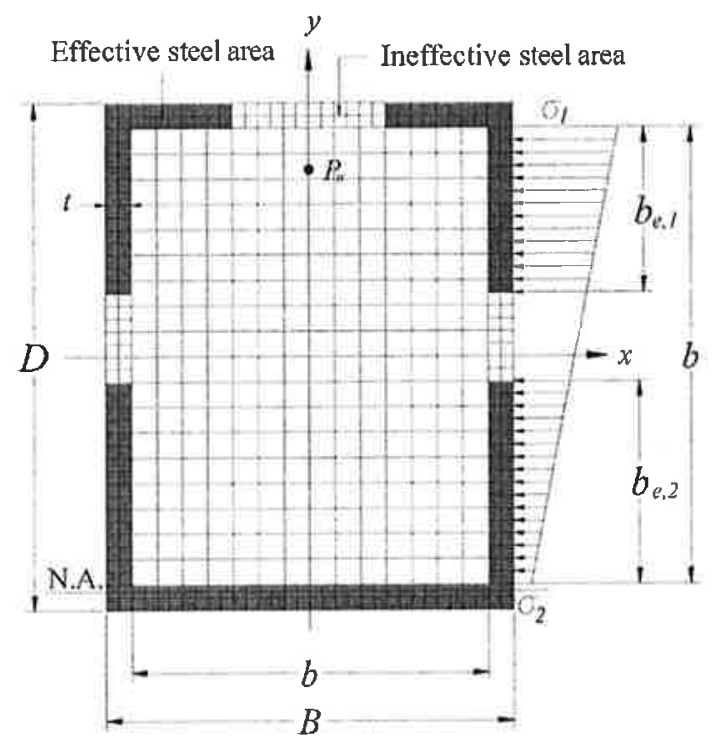

Fig. 1 Fiber element discretization of CFST column section

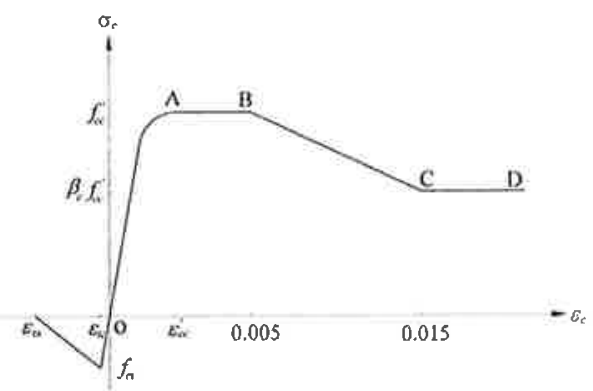

(a)

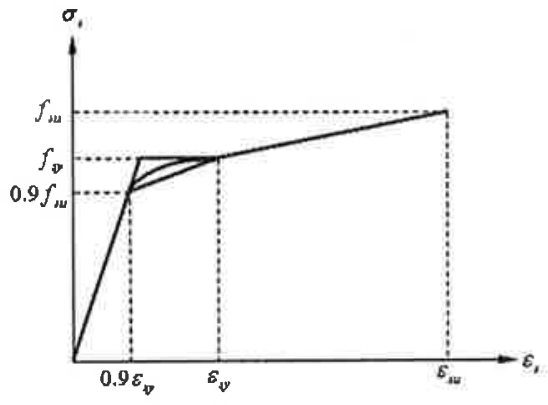

(b)

Fig. 2 Material constitutive models: (a) concrete and (b) structural steels

\subsection{Material constitutive model for concrete}

The confinement provided by the steel tube increases the ductility of the concrete core in a

CFST column but not its compressive strength. A general stress-strain curve for concrete in CFST columns shown in Fig. 2(a) is used in the mesoscale model (Liang 2009a). The part OA of stressstrain curve is modeled using the equations suggested by Mander et al. (1988) as

$$
\begin{gathered}
\sigma_{c}=\frac{f_{c c}^{\prime} \lambda\left(\varepsilon_{c} / \varepsilon_{c c}^{\prime}\right)}{\lambda-1+\left(\varepsilon_{c} / \dot{\varepsilon}_{c c}^{\prime}\right)^{\lambda}} \\
\lambda=\frac{E_{c}}{E_{c}-\left(f_{c c}^{\prime} / \varepsilon_{c c}^{\prime}\right)}
\end{gathered}
$$




$$
E_{c}=3320 \sqrt{f_{c c}^{\prime}}+6900(\mathrm{MPa})
$$

where $\sigma_{c}$ is the compressive concrete stress, $f_{c c}^{\prime}$ is the effective compressive strength of concrete, $\varepsilon_{c}$ is the compressive concrete strain and $\varepsilon_{c c}^{\prime}$ is the strain at $f_{c c}^{\prime}$ and $E_{c}$ is the Young's modulus of concrete. The strain $\varepsilon_{c c}^{\prime}$ is between 0.002 and 0.003 depending on the effective compressive strength of concrete (Liang 2009a). The effective compressive strength of concrete $\left(f_{c c}^{\prime}\right)$ is taken as $\gamma_{c} f_{c}^{\prime}$, where $\gamma_{c}$ is the strength reduction factor proposed by Liang (2009a) to account for the column size effect and is expressed by

$$
\gamma_{c}=1.85 D_{c}^{-0.135} \quad\left(0.85 \leq \gamma_{c}<1.0\right)
$$

where $D_{c}$ is taken as the larger of $(B-2 t)$ and $(D-2 t)$ for a rectangular cross-section, $B$ is the width of the cross-section, $D$ is the depth of the cross-section and $t$ is the thickness of the steel tube wall as shown in Fig. 2(a).

The model for parts $A B, B C$ and $C D$ of the stress-strain curve for concrete as shown in Fig. 2(a) was given by Liang (2009a) as

$$
\sigma_{c}= \begin{cases}f_{c c}^{\prime} & \text { for } \varepsilon_{c c}^{\prime}<\varepsilon_{c}<0.005 \\ \beta_{c} f_{c c}^{\prime}+100\left(0.015-\varepsilon_{c}\right)\left(f_{c c}^{\prime}-\beta_{c} f_{c c}^{\prime}\right) & \text { for } 0.005<\varepsilon_{c} \leq 0.015 \\ \beta_{c} f_{c c}^{\prime} & \text { for } \varepsilon_{c}>0.015\end{cases}
$$

where $\beta_{c}$ was proposed by Liang (2009a) based on experimental results presented by Tomii and Sakino (1979) and is given by

$$
\beta_{c}= \begin{cases}1.0 & \text { for } B_{s} / t \leq 24 \\ 1.5-B_{s} / 48 t & \text { for } 24<B_{s} / t \leq 48 \\ 0.5 & \text { for } B_{s} / t>48\end{cases}
$$

where $B_{s}$ is taken as the larger of $B$ and $D$ for a rectangular cross-section.

The stress-strain curve for concrete in tension is shown in Fig. 2(a). The concrete tensile strength is taken as $0.6 \sqrt{f_{c c}^{\prime}}$ and ultimate strain is taken as 10 times of the strain at cracking.

\subsection{Material constitutive model for structural steels}

Steel tubes are usually made of high strength structural steel, cold-formed steel or mild structural steel. For mild structural steels, an idealized tri-linear stress-strain curve is assumed as shown in Fig. 2(b), where fsy and fsu are the yield stress and tensile strength of the steel respectively. An idealized linear-rounded-linear stress-strain curve is used for cold-formed steels. The rounded part in the curve can be modeled by a formula proposed by Liang (2009a). For high strength steels, the rounded part is replaced by a straight line. 


\subsection{Local and post-local buckling}

The effects of local and post-local buckling of high strength CFST beam-columns are taken into account in the mesoscale model. For a CFST column under axial load and bending, the steel tube walls may be subjected to compressive stress gradients as depicted in Fig. 1. The classical elastic local buckling theory cannot be used to determine the initial local buckling stress of thin steel plates with initial geometric imperfections (Liang et al. 2007). The formulas proposed by Liang et al. (2007) are therefore incorporated in the mesoscale model to determine the initial local buckling stresses of steel tube walls under stress gradients.

The effective width concept is usually used to determine the post-local buckling strength of thin steel plates under uniform compression or stress gradients as shown in Fig. 1. The effective widths $b_{e 1}$ and $b_{e 2}$ shown in Fig. 1 are given by Liang et al. (2007)

$$
\begin{gathered}
\frac{b_{e 1}}{b}=\left\{\begin{array}{cl}
0.2777+0.01019(b / t)-1.972 \times 10^{-4}(b / t)^{2}+9.605 \times 10^{-7}(b / t)^{3} & \text { for } \alpha_{s}>0.0 \\
0.4186-0.002047(b / t)+5.355 \times 10^{-5}(b / t)^{2}-4.685 \times 10^{-7}(b / t)^{3} & \text { for } \alpha_{s}=0.0
\end{array}\right. \\
\frac{b_{e 2}}{b}=\left(2-\alpha_{s}\right) \frac{b_{e 1}}{b}
\end{gathered}
$$

where $b$ is the clear width of a steel web or flange of the box section, and $\alpha_{s}=\sigma_{2} / \sigma_{1}$, where $\sigma_{1}$ and $\sigma_{2}$ are the maximum and minimum edge stresses acting on the steel tube wall.

In the mesoscale model, the progressive post-local buckling is modeled by gradually redistributing the normal stresses within the steel tube wall under increasing compression load based on the stress levels (Liang 2009a). After initial local buckling, steel fiber stresses are updated to account for postlocal buckling effects.

\subsection{Stress resultants}

Axial force and moments carried by a CFST column section are determined as stress resultants by integration as follows

$$
\begin{gathered}
P=\sum_{i=1}^{n s} \sigma_{s, i} A_{s, i}+\sum_{j=1}^{n c} \sigma_{c, j} A_{c, j} \\
M_{x}=\sum_{i=1}^{n s} \sigma_{s, i} A_{s, i} y_{i}+\sum_{j=1}^{n c} \sigma_{c, j} A_{c, j} y_{j} \\
M_{y}=\sum_{i=1}^{n s} \sigma_{s, i} A_{s, i} x_{i}+\sum_{j=1}^{n c} \sigma_{c, j} A_{c, j} x_{j}
\end{gathered}
$$

where $P$ is the axial force, $\sigma_{s, i}$ is the stress of steel fiber $i, A_{s, i}$ is the area of steel fiber $i, \sigma_{c, j}$ is the stress of concrete fiber $j, A_{c, j}$ is the area of concrete fiber $j, x_{i}$ and $y_{i}$ are the coordinates of 


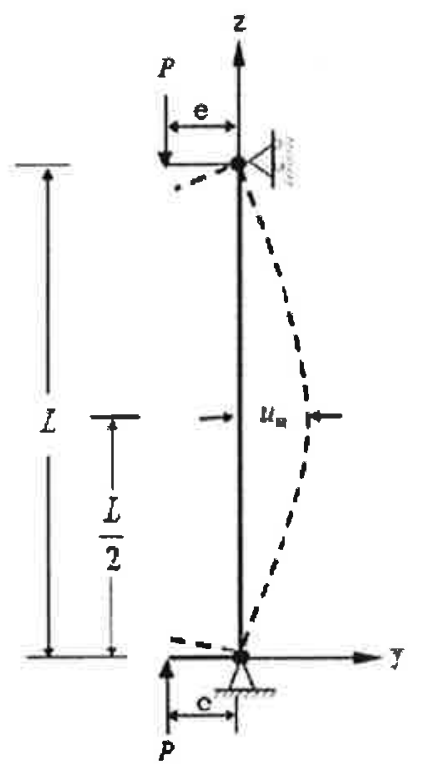

Fig. 3 Pin-ended beam-column model

steel element $i, x_{j}$ and $y_{j}$ are the coordinates of concrete element $j, n s$ is the total number of steel fiber elements and $n c$ is the total number of concrete fiber elements.

\section{Macroscale simulation}

\subsection{Macroscale model}

The macroscale model for a pin-ended beam-column under axial load at an eccentricity $e$ is shown in Fig. 3. The deflected shape of the beam-column is assumed to be part of sine wave and is expressed by

$$
u=u_{m} \sin \left(\frac{\pi z}{L}\right)
$$

where $L$ is the effective length of the beam-column and $u_{m}$ is the deflection at the mid-height.

The curvature at the mid-height of the beam-column can be obtained as

$$
\phi_{m}=\left(\frac{\pi}{2}\right)^{2} u_{m}
$$

The external moment at the mid-height of the beam-column with an initial geometric imperfection $u_{o}$ at the mid-height can be calculated by

$$
M_{m e}=P\left(e+u_{m}+u_{o}\right)
$$

To compute the load-deflection curve for a CFST slender beam-column under eccentric loading, the deflection at the column mid-height $\left(u_{m}\right)$ is gradually increased. The curvature $\phi_{m}$ at the 
column mid-height is computed from the deflection $u_{m}$. The neutral axis depth is then adjusted to achieve the moment equilibrium at the mid-height of the beam-column. The following equilibrium equation must be satisfied

$$
P\left(e+u_{m}+u_{o}\right)-M_{m i}=0
$$

where $M_{m i}$ is the internal moment carried by the section.

\subsection{Numerical solution method}

Iterative numerical algorithms based on the Müller's method (Müller 1956) are developed to obtain nonlinear solutions (Patel et al. 2012a, b). The Müller's method requires three starting values of the neutral axis depth $d_{n, 1}, d_{n, 2}$ and $d_{n, 3}$. The corresponding residual moments $r_{p u, 1}, r_{p u, 2}$ and $r_{p u, 3}$ are calculated from these initial values. The new neutral axis depth $d_{n, 4}$ that approaches the true value is determined by the following equations

$$
\begin{gathered}
d_{n, 4}=d_{n, 3}+\frac{-2 c_{m}}{b_{m} \pm \sqrt{b_{m}^{2}-4 a_{m} c_{m}}} \\
a_{m}=\frac{\left(d_{n, 2}-d_{n, 3}\right)\left(r_{p u, 1}-r_{p u, 3}\right)-\left(d_{n, 1}-d_{n, 3}\right)\left(r_{p u, 2}-r_{p u, 3}\right)}{\left(d_{n, 1}-d_{n, 2}\right)\left(d_{n, 1}-d_{n, 3}\right)\left(d_{n, 2}-d_{n, 3}\right)} \\
b_{m}=\frac{\left(d_{n, 1}-d_{n, 3}\right)^{2}\left(r_{p u, 2}-r_{p u, 3}\right)-\left(d_{n, 2}-d_{n, 3}\right)^{2}\left(r_{p u, 1}-r_{p u, 3}\right)}{\left(d_{n, 1}-d_{n, 2}\right)\left(d_{n, 1}-d_{n, 3}\right)\left(d_{n, 2}-d_{n, 3}\right)} \\
c_{m}=r_{p u, 3}
\end{gathered}
$$

where $r_{p u}$ is the residual moment at the mid-height of the column, which is given by

$$
r_{p u}=P\left(e+u_{m}+u_{o}\right)-M_{m i}
$$

To obtain converged solutions, the values of $d_{n, 1}, d_{n, 2}$ and $d_{n, 3}$ and residual moments $r_{p u, 1}$, $r_{p u_{0}, 2}$ and $r_{p u, 3}$ need to be exchanged and Eq. (16) is used to adjust the $d_{n}$ (Patel et al. 2012a).

\subsection{Computational procedure}

Computational algorithms have been developed to implement the macroscale model for thinwalled CFST slender beam-columns incorporating the mesoscale model. The main steps of the computational procedure are given as follows:

(1) Discretize composite section into fine fiber elements.

(2) Initialize the mid-height deflection: $u_{m}=\Delta u_{m}$.

(3) Compute the curvature $\phi_{m}$ at the mid-height of the slender beam-column.

(4) Initialize $d_{n, 1}=D / 4, d_{n, 2}=D / 2$ and $d_{n, 3}=D$.

(5) Calculate fiber stresses using material models.

(6) Check local buckling and redistribute steel fiber stresses accordingly.

(7) Compute internal moment $M_{m i}$ and external moment $M_{m e}$.

(8) Calculate residual moments $r_{p u, 1}, r_{p u, 2}$ and $r_{p u, 3}$ corresponding to $d_{n, 1}, d_{n, 2}$ and $d_{n, 3}$.

(9) Adjust the neutral axis depth $d_{n}$ using the Müller's method. 
(10) Calculate fiber stresses using material models.

(11) Check local buckling and redistribute steel fiber stresses accordingly.

(12) Compute internal moment $M_{m i}$ and external moment $M_{m e}$.

(13) Repeat Steps (9)-(12) until $\left|r_{p u}\right|<10^{-4}$.

(14) Increase the mid-height deflection of the beam-column by $u_{m}=u_{m}+\Delta u_{m}$.

(15) Repeat Steps (3)-(14) until the ultimate load $P_{u}$ is obtained or the deflection limit is reached.

(16) Plot the axial load-deflection curve.

\section{Performance indices}

Performance indices that evaluate the contributions of steel and concrete components to the ultimate strengths of CFST slender beam-columns can be used to study economical composite designs. The steel contribution ratio is used to quantify the contribution of the hollow steel tubular column to the ultimate strength of the CFST slender beam-column and is defined as

$$
\xi_{s}=\frac{P_{u \text { steel }}}{P_{u}}
$$

where $P_{\text {u.steel }}$ is the ultimate axial strength of the calculated hollow steel slender beam-column and $P_{u}$ is the ultimate axial strength of the CFST slender beam-column. The ultimate axial strength $P_{\text {u.steel }}$ is calculated by setting the concrete compressive strength to zero in the numerical analysis while other conditions remain the same as the CFST beam-column.

The concrete contribution ratio is used to determine the contribution of the concrete core to ultimate strength of the CFST slender beam-column, which is defined as

$$
\xi_{c}=\frac{P_{u}-P_{u . s t e e l}}{P_{u}}
$$

The strength reduction factor is used to measure the performance of a CFST slender beam-column over its section and is defined as

$$
\alpha_{c}=\frac{P_{u}}{P_{o}}
$$

where $P_{o}$ is the ultimate axial strength of the beam-column section under axial compression.

\section{Verification}

The ultimate axial strengths of uniaxially loaded CFST slender beam-columns predicted by the numerical model are compared with experimental results in Table 1, where Es is the Young's modulus. Specimens SCH-1, SCH-2 and SCH-7 were tested by Bridge (1976) while test results of specimens $E 03, E 04, E 07, E 08, E 11, E 12, L 1, L 2, L 3$ and $L 4$ were provided by Liu $(2004,2006)$ and specimens $M 1, M 4, M 6, M 7$ and $M 8$ were tested by Zhang et al. (2003). In Table 1, the concrete cylinder compressive strength $\left(f_{c}^{\prime}\right)$ was taken as 0.85 times the concrete cube compressive strength $\left(f_{c u}\right)$. It can be observed from Table 1 that the predicted ultimate axial strengths are in good agreement with corresponding test results. The mean value of the predicted axial strength 
Inelastic stability analysis of high strength rectangular concrete-filled steel tubular slender beam-columns 99

Table 1 Comparison of predicted and experimental ultimate axial strengths of CFST columns

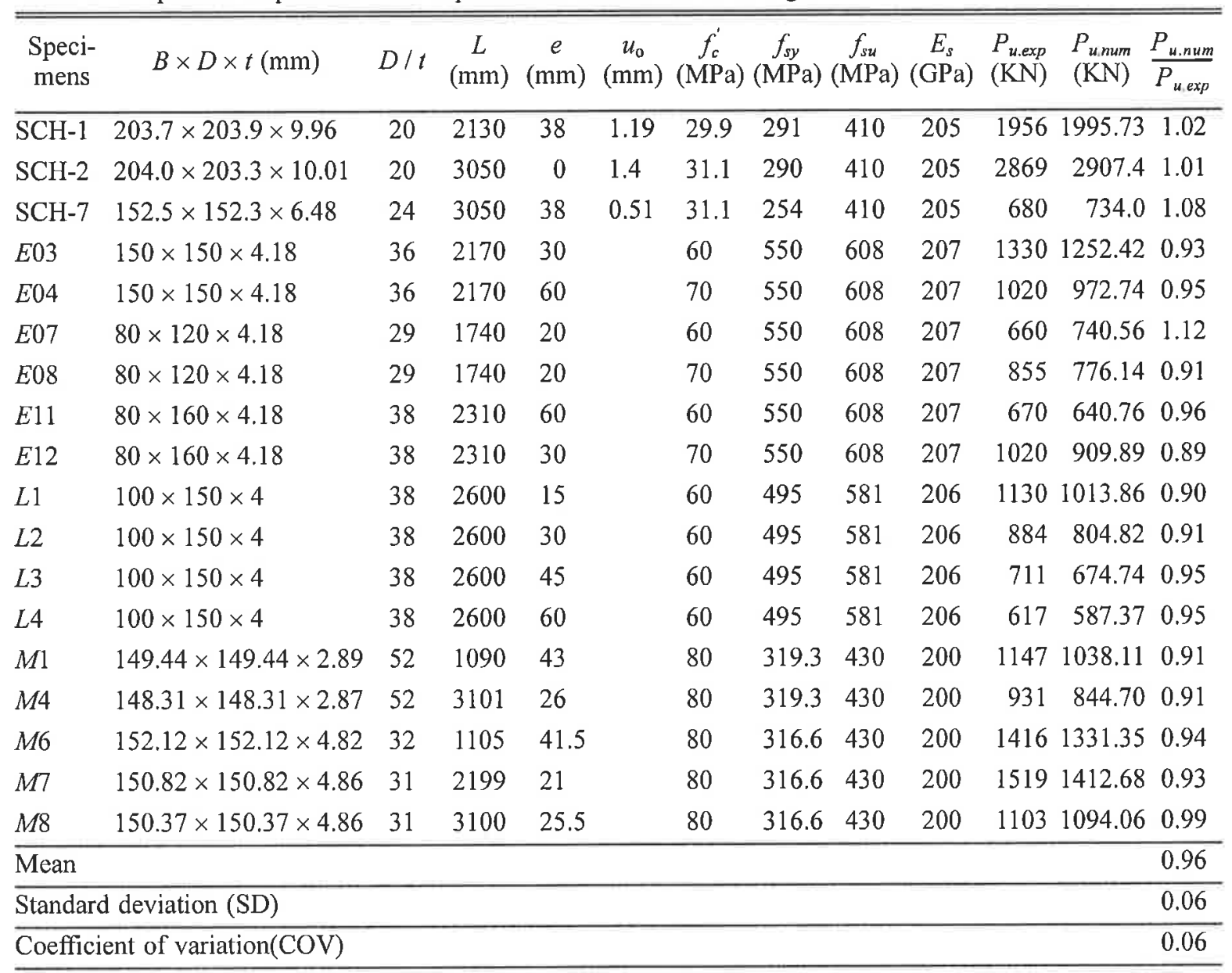

$\left(P_{u, n u m}\right)$ to the experimental value $\left(P_{u . \exp }\right)$ is 0.96 with a standard deviation of 0.06 and the coefficient of variation of 0.06 . Fig. 4 shows the predicted and experimental load-deflection curves for specimens $L 3$ and $L 4$. It can be seen from the figure that the numerical model predicts well the load-deflection responses of the specimens. It can be concluded that the numerical model yields good predications of the nonlinear inelastic behavior of normal and high strength CFST slender beam-columns.

\section{Applications}

The numerical model developed was used to investigate the effects of concrete compressive strength, loading eccentricity ratio $(e / D)$, depth-to-thickness ratio $(D / t)$ and column slenderness ratio $(L / r)$ on the performance indices. The following parameters are kept constant in the present parametric study. The initial geometric imperfection at the mid-height of the beam-column was taken as $L / 1500$. The yield and tensile strengths of the steel tubes were 690 and $790 \mathrm{MPa}$ respectively. The Young's modulus of steel was $200 \mathrm{GPa}$. 


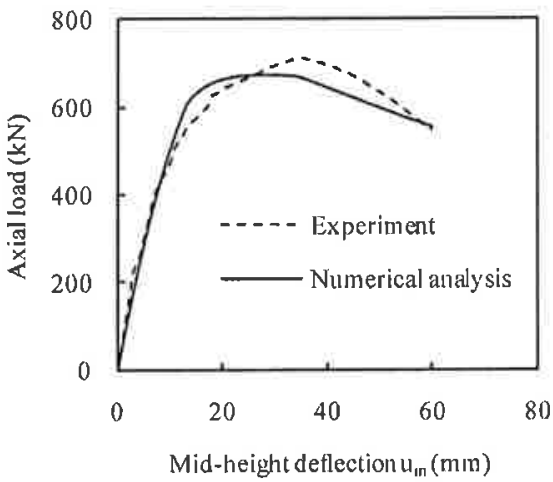

(a) Specimen $L 3$

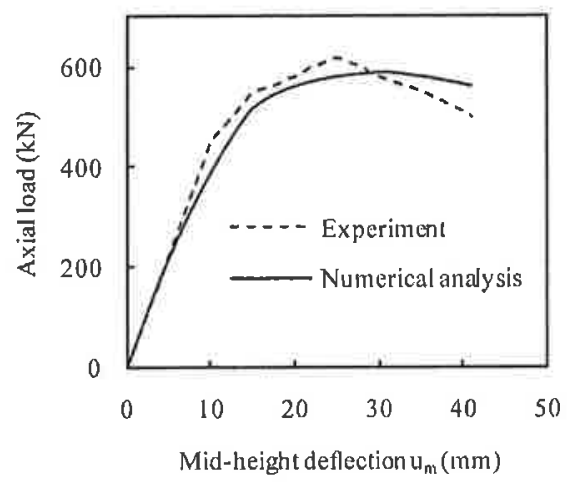

(b) Specimen $L 4$

Fig. 4 Comparison of predicted and experimental axial load-deflection curves

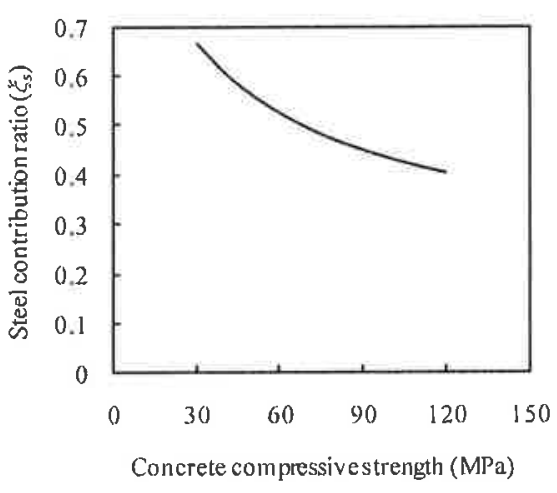

(a)

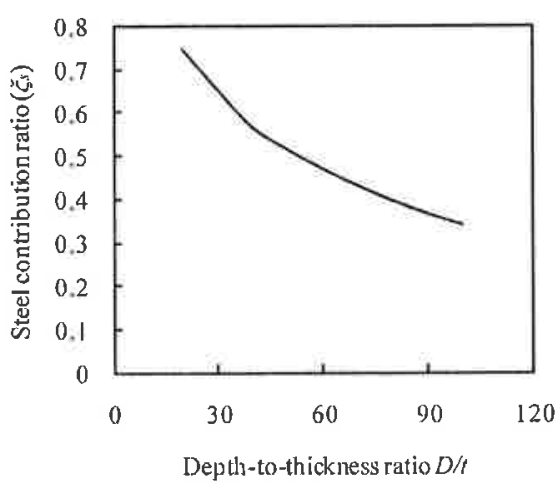

(c)

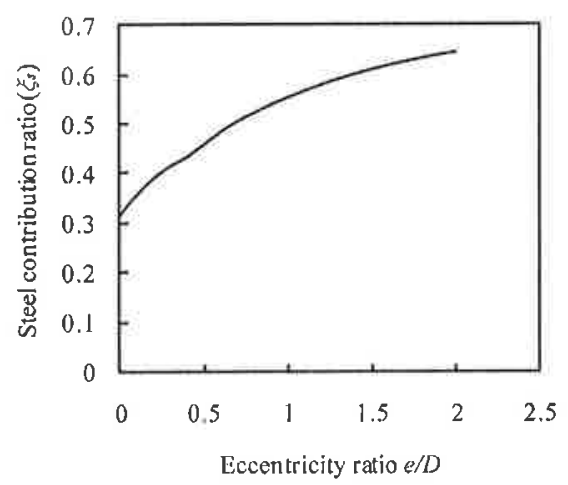

(b)

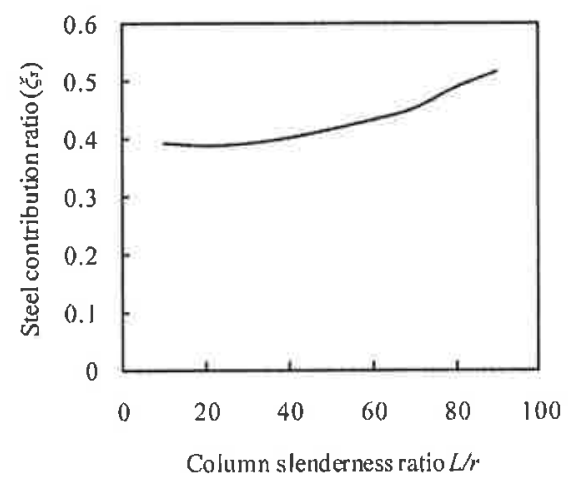

(d)

Fig. 5 Steel contribution ratio

\subsection{Steel contribution ratio}

A column cross-section of $600 \times 700 \mathrm{~mm}$ was considered in the study of steel contribution ratio. The depth-to-thickness ratio of 70 , the column slenderness ratio of 60 and the loading eccentricity 
Inelastic stability analysis of high strength rectangular concrete-filled steel tubular slender beam-columns 101

ratio of 0.4 were used to examine the effects of concrete compressive strengths. Fig. 5(a) shows that increasing the concrete compressive strength appreciably reduces the steel contribution ratio. The steel contribution ratio of a CFST slender beam-column with concrete compressive strength of 30 $\mathrm{MPa}$ is 0.67 and it is only 0.40 when $120 \mathrm{MPa}$ concrete is used. Fig. 5(b) depicts the effects of the loading eccentricity ratio on the steel contribution ratio of the beam-column filled with $100 \mathrm{MPa}$ concrete. It would appear from Fig. 5(b) that the steel contribution ratio considerably increases with increasing the end eccentricity ratio. For the end eccentricity ratios of zero and two, the steel contribution ratios are 0.31 and 0.65 respectively.

Fig. 5(c) illustrates the effects of depth-to-thickness ratio on the steel contribution ratio of CFST slender beam-columns filled with $100 \mathrm{MPa}$ concrete. It can be seen from figure that the steel contribution ratio decreases with an increase in the depth-to-thickness ratio. This may be attributed to the fact that the steel area in column section and the local buckling strength of the steel tube decreases with an increase the depth-to-thickness ratio. The effects of column slenderness ratio on the steel contribution ratio of thin-walled CFST beam-columns are shown in Fig. 5(d). The steel contribution ratios are $0.39,0.42$ and 0.56 for the columns with slenderness ratios of 10,50 and 90 respectively. This indicates that the use of slender columns increases their seel contribution ratio. Fig. 6 shows that local buckling remarkably reduces the stiffness and overall buckling strength of the CFST slender beam-column with the $D / t$ ratio of $100, e / D$ of $0.4, L / r$ ratio of 40 and concrete compressive strength of $100 \mathrm{MPa}$. The overall buckling strength of the slender beam-column is overestimated by $6.73 \%$ if local buckling was not considered. This highlights the importance of considering local buckling effects in the inelastic stability analysis of thin-walled CFST slender beam-columns.

\subsection{Concrete contribution ratio}

The concrete contribution was evaluated on a CFST slender beam-column with the cross-section of $700 \times 700 \mathrm{~mm}$. To study the effects of concrete compressive strengths, loading eccentricity ratio of 0.4 , the depth-to-thickness ratio of 50 and the column slenderness ratio of 35 were considered. It is observed from Fig. 7(a) that the concrete contribution ratio increases with an increase in the

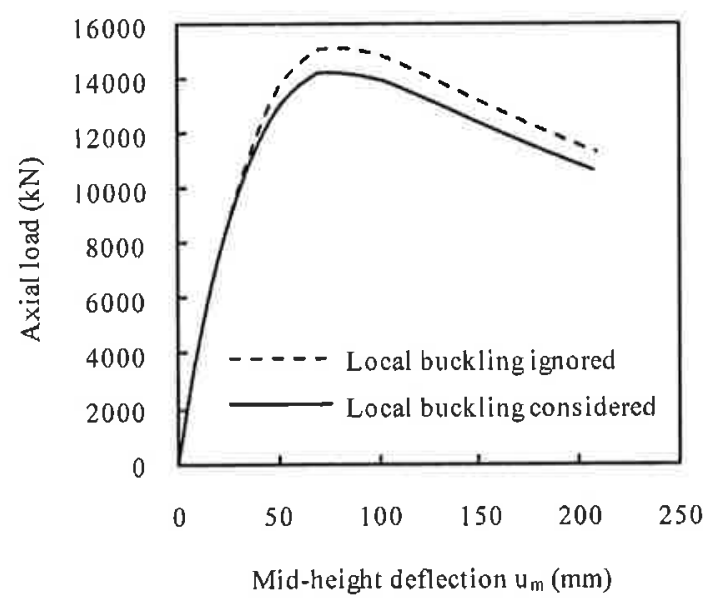

Fig. 6 Effects of local buckling on the axial load-deflection curve for thin-walled CFST slender beam-column 


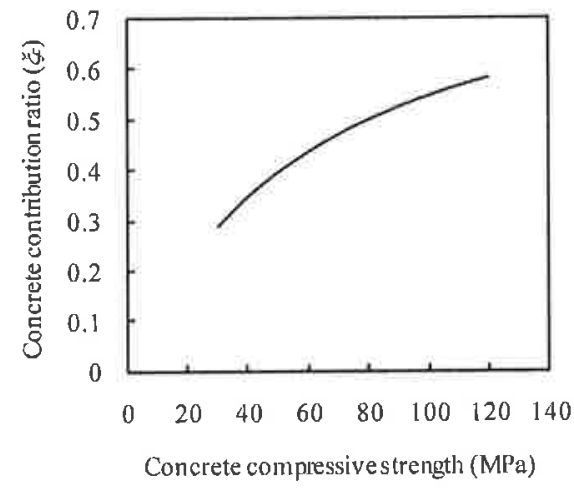

(a)

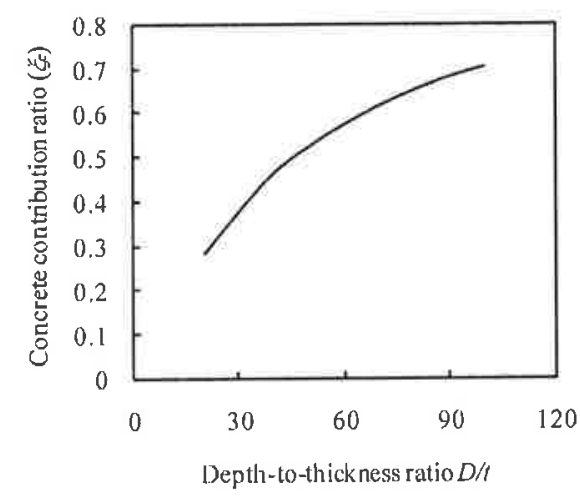

(c)

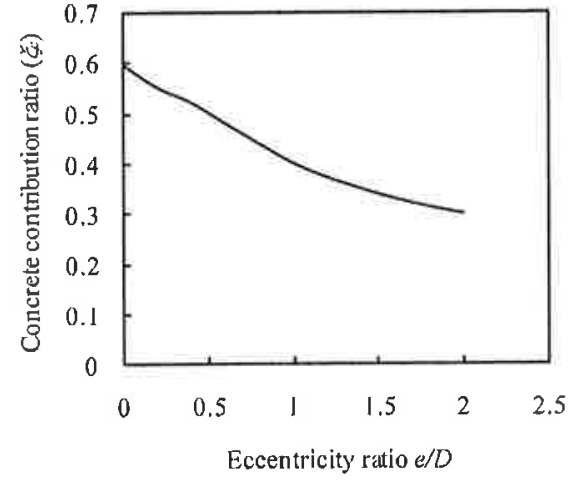

(b)

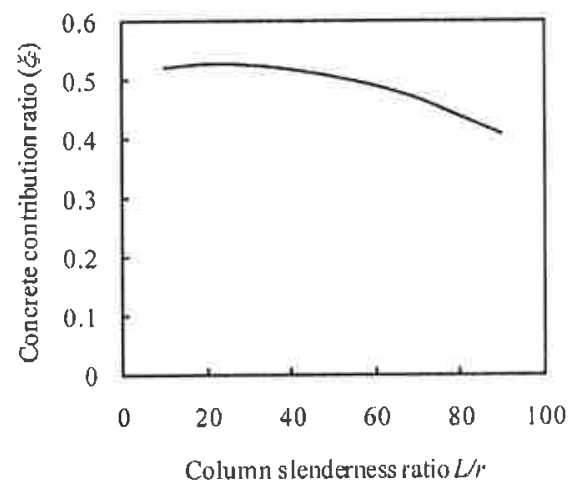

(d)

Fig. 7 Concrete contribution ratio

concrete compressive strength. Fig. 7(b) shows the effects of the loading eccentricity ratio on the concrete contribution ratio of the beam-column filled with $90 \mathrm{MPa}$ concrete. It appears that increasing the loading eccentricity ratio significantly reduces the concrete contribution ratio of CFST slender beam-columns.

The effects of depth-to-thickness ratio and column slenderness ratio on the concrete contribution ratio of the beam-columns filled with $90 \mathrm{MPa}$ concrete are shown in Fig. 7(c) and Fig. 7(d) respectively. It can be seen from Fig. 7(c) that increasing the depth-to-thickness ratio significantly increases the concrete contribution ratio. Fig. 7(d) shows that increasing the column slenderness ratio decreases the concrete contribution ratio.

\subsection{Strength reduction factor}

The cross-section of a CFST slender beam-column used in the analysis was $500 \times 600 \mathrm{~mm}$. The depth-to-thickness ratio of 60 , loading eccentricity ratio of 0.4 and the slenderness ratio of 60 were used to study the effects of concrete compressive strengths. Fig. 8(a) indicates that increasing the concrete compressive strength significantly reduces the strength reduction factor. The effects of loading eccentricity ratio on the strength reduction factor of the beam-columns filled with $80 \mathrm{MPa}$ concrete are presented in Fig. 8(b). It appears from Fig. 8(b) that the strength reduction factor 
Inelastic stability analysis of high strength rectangular concrete-filled steel tubular slender beam-columns 103

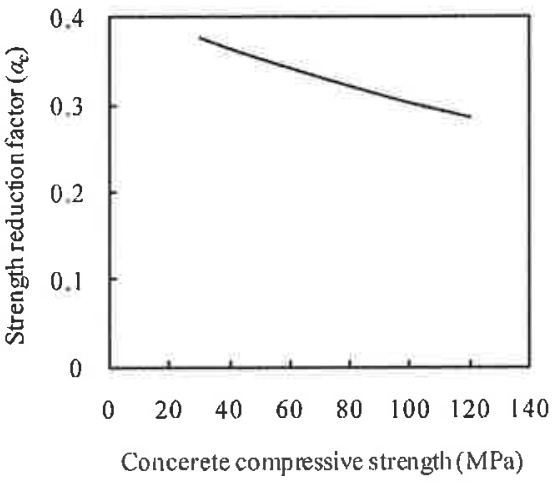

(a)

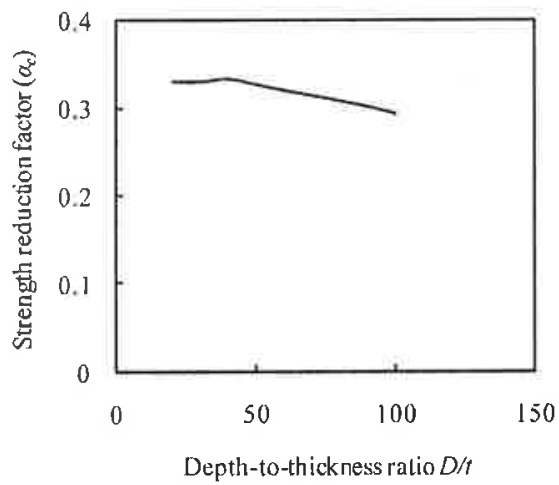

(c)

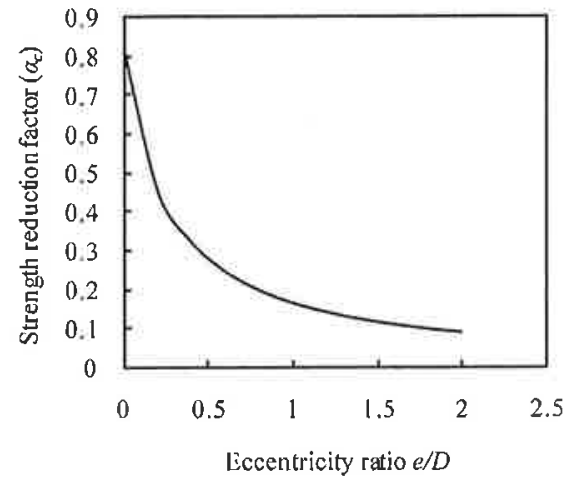

(b)

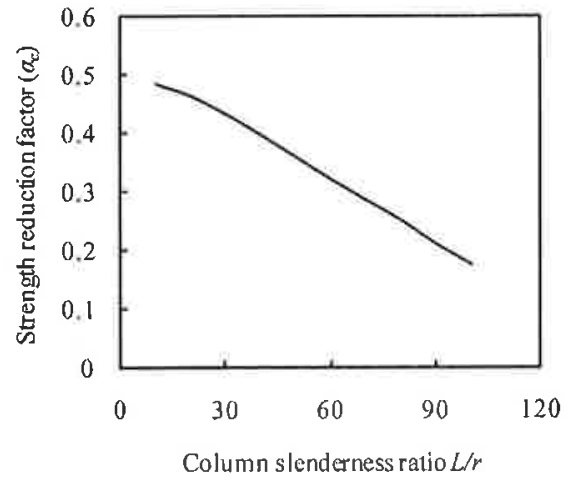

(d)

Fig. 8 Strength reduction factor

decreases with an increase in the $e / D$ ratio. Fig. 8(c) shows the effects of depth-to-thickness ratio on the strength reduction factor of the columns with $80 \mathrm{MPa}$ concrete. It can be seen from Fig. 8(c) that the strength reduction factor decreases with an increase in the $D / t$ ratio for the same size composite section. As shown in Fig. 8(d), the strength reduction factor appears to decrease with an increase in its $L / r$ ratio.

\section{Conclusions}

This paper has presented a multiscale numerical model for simulating the interaction local and global bucking behavior of high strength rectangular CFST slender beam-columns under axial load and bending. The effects of progressive local buckling of the steel tube walls under stress gradients are accounted for in the mesoscale model based on the accurate fiber element method. Computational algorithms have been developed to implement the macroscale model for predicting the load-deflection responses of high strength CFST slender beam-columns. The verification and applications of the multiscale model demonstrate that the multiscale numerical model developed is accurate and efficient for the inelastic stability analysis of high strength CFST slender beamcolumns with large depth-to-thickness ratios. 


\section{References}

Bridge, R.Q. (1976), "Concrete filled steel tubular columns", School of Civil Engineering, The University of Sydney, Sydney, Australia, Research Report No. R 283.

Ellobody, E., Young, B. and Lam, D. (2006), "Behaviour of normal and high strength concrete-filled compact steel tube circular stub columns", J. Constr. Steel Res., 62(7), 706-715.

Han, L.H. (2002), "Tests on stub columns of concrete-filled RHS sections", J. Constr. Steel Res., 58(3), 353-372.

Hu, H.T., Huang, C.S., Wu, M.H. and Wu, Y.M. (2003), "Nonlinear analysis of axially loaded concrete-filled tube columns with confinement effect", J. Struct. Eng.-ASCE, 129(10), 1322-1329.

Lakshmi, B. and Shanmugam, N.E. (2002), "Nonlinear analysis of in-filled steel-concrete composite columns", J. Struct. Eng. $-A S C E$, 128(7), 922-933.

Laskar, A., Zhong, J., Mo, Y.L. and Hsu, T.T.C. (2009), "Multiscale modeling of reinforced/prestressed concrete thin-walled structures", Interact. Multiscale Mech., 2(1), 69-89.

Liang, Q.Q. (2009a), "Performance-based analysis of concrete-filled steel tubular beam-columns, Part I: Theory and algorithms", J. Constr. Steel Res., 65(2), 363-372.

Liang, Q.Q. (2009b), "Performance-based analysis of concrete-filled steel tubular beam-columns, Part II: Verification and applications", J. Constr. Steel Res., 65(2), 351-362.

Liang, Q.Q. (2011a), "High strength circular concrete-filled steel tubular slender beam-columns, Part I: Numerical analysis", J. Constr. Steel Res., 67(2), 164-171.

Liang, Q.Q. (2011b), "High strength circular concrete-filled steel tubular slender beam-columns, Part II: Fundamental behavior", J. Constr. Steel Res., 67(2), 172-180.

Liang, Q.Q., Uy, B. and Liew, J.Y.R. (2007), "Local buckling of steel plates in concrete-filled steel tubular beamcolumns", J. Constr. Steel Res., 63(3), 396-405.

Liu, D. (2004), "Behaviour of high strength rectangular concrete-filled steel hollow section columns under eccentric loading", Thin Wall. Struct., 42(12), 1631-1644.

Liu, D. (2006), "Behaviour of eccentrically loaded high-strength rectangular concrete-filled steel tubular columns", J. Constr. Steel Res., 62(8), 839-846.

Mander, J.B., Priestly, M.N.J. and Park, R. (1988), "Theoretical stress-strain model for confined concrete", J. Struct. Eng.-ASCE, 114(8), 1804-1826.

Müller, D.E. (1956), "A method for solving algebraic equations using an automatic computer", $M T A C, 10(56)$, 208-215.

Nagarajan, P., Jayadeep, U.B. and Pillai, T.M.M. (2010), "Mesoscopic numerical analysis of reinforced concrete beams using a modified micro truss model", Interact. Multiscale Mech., 3(1), 23-37.

Patel, V.I., Liang, Q.Q. and Hadi, M.N.S. (2012a), "High strength thin-walled rectangular concrete-filled steel tubular slender beam-columns, Part I: Modeling", J. Constr. Steel Res., 70, 377-384.

Patel, V.I., Liang, Q.Q. and Hadi, M.N.S. (2012b), "High strength thin-walled rectangular concrete-filled steel tubular slender beam-columns, Part II: Behavior", J. Constr. Steel Res., 70, 368-376.

Sakino, K., Nakahara, H., Morino, S. and Nishiyama, I. (2004), "Behavior of centrally loaded concrete-filled steel-tube short columns", J. Struct. Eng.-ASCE, 130(2), 180-188.

Schneider, S.P. (1998), "Axially loaded concrete-filled steel tubes", J. Struct. Eng.-ASCE, 124(10), 1125-1138.

Shakir-Khalil, H. and Zeghiche, J. (1989), "Experimental behaviour of concrete-filled rolled rectangular hollowsection columns", Struct. Eng, 67(19), 346-353.

Tomii, M. and Sakino, K. (1979), "Elastic-plastic behaviour of concrete filled square steel tubular beamcolumns", Trans. Arch. Inst, 280, 111-120.

Zhang, S., Guo, L. and Tian, H. (2003), "Eccentrically loaded high strength concrete-filled square steel tubes", Adv. Struct., Proc. of the Int. Conf. on Advances in Structures, Sydney, Australia. 